\title{
AOS QUE AINDA ESCREVEM: A ESCRITA ACADÊMICA NOS DESIGNS DO NEOLIBERALISMO
}

Luciano Bedin da Costa ${ }^{1}$

Este ensaio é dedicado ao ainda, aos que ainda escrevem apesar de tudo. $\mathrm{O}$ ainda é aqui um ranço, uma resistência e também uma política.

Como na roleta e no pôquer: mesmo mortos de cansaço, continuamos a nos agarrar com uma vitalidade surpreendente.

Félix Guattari, Confrontações

Ainda não entendemos o que é o neoliberalismo, e estamos pagando um preço altíssimo por isso.

Dardot \& Laval, A nova razão do mundo

Haveria o dia em que as universidades públicas seriam colocadas na mira dos tiros. Apesar do significativo crescimento do ensino superior em nosso país, verificado com a criação de novas universidades públicas ao longo dos últimos 15 anos e com o ingresso de diferenças historicamente segregadas - como o caso dos povos indígenas, afrodescendentes, transexuais e portadores de deficiências -, o que percebemos é que não conseguimos constituir um imaginário social capaz de suportar a violência dos ataques atuais a que estamos submetidos. Diante da investida neoliberal em prol do desmonte das instituições públicas em geral - em nome das proferidas "concessões", "parcerias público-privadas", "privatizações” ou, em seu eufemismo atual, das "desestatizações" - acabamos nos vendo encurralados por discursos de fácil digestão, discursos mais ou menos convincentes que colocam a universidade, como os demais dispositivos públicos, na condição de maquinarias do engodo, engenhocas supostamente pesadas demais e incapazes de lidar com as demandas por flexibilidade e dinamicidade, dois significantes que nos chegam como verdadeiros mantras do liberalismo contemporâneo.

Se, por um lado, é necessário cada vez mais defendermos o que julgamos serem grandes conquistas e garantias sociais, por outro é vital que estejamos suficientemente atentos para que possamos nos pensar em meio a tudo isso. Não se trata de pensarmos "onde foi que erramos?" ou “quem não nos deixou ser o que gostaríamos de ser?", questionamentos que nos levam a um infecundo jogo de culpabilização, mas da necessidade de arquitetarmos arranjos éticos outros diante de tais forças. Pensar que estamos "caminhando para trás", embora possa ser paradoxalmente confortador, não nos parece producente. Talvez a questão seja a de que "estamos indo muito rapidamente para frente", tão rapidamente que nos vemos incapazes de perceber a sutileza de nossa própria resistência e das coletividades que resistem nos cantos, nas dobras, nas arestas e lateralidades. Faz-se necessário destacar que nunca, na brevíssima história democrática de nosso país, tivemos tantos movimentos de contestação e insatisfação sociais. No entanto, mesmo com tantos levantes fica a sensação de que estamos resignados, o que,

\footnotetext{
${ }^{1}$ Docente da Faculdade de Educação e do Programa de Pós-Graduação em Psicologia Social e Institucional da Universidade Federal do Rio Grande do Sul - UFRGS. E-mail: bedin.costa@gmail.com.
} 
segundo Birman (2006), é fruto da pulverização das próprias forças de resistência, não mais diante de um grande inimigo - o Soberano -, mas de soberanias microfísicas, o que torna dificultosa a percepção de que estamos - mesmo com pautas aparentemente diferentes - em um mesmo e grande barco.

O que observamos em meio a esse acelerado desmantelamento nos parece muito mais do que um projeto ideologicamente neoliberal de destruição da dita coisa pública, mas uma complexa maquinaria de colonização do desejo e do imaginário político das coletividades. Tão nefasto quanto o corte e congelamento substancial de recursos financeiros, parece-nos o processo de subnutrição de nossa imaginação política, da capacidade de coletivamente imaginarmos estratégias de resistência diante do que nos assombra nessa voraz e veloz noite que parece não ter fim.

\section{Um novo design psicológico}

Quando estamos em meio a um pesadelo, imersos aos urros, monstros e fantasmas, acabamos por nos esquecer dos assombros do dia, das assombrações ainda mais noturnas do que a própria noite que as alimenta. Não é preciso nos deitarmos em um divã para nos darmos conta de que a história de nossas experiências diurnas, tecida em uma rede de acasos, contingências e também de responsabilizações, é o que alimenta nossos próprios monstros noturnos, uma história passível de ser narrada, embora nunca plenamente reconstituída.

Ao pensarmos no pesadelo neoliberal em que nos encontramos, na voraz distopia do Estado Social, somos inevitavelmente levados a pensar no colapso da esquerda de um modo geral. De acordo com Safatle (2017, p. 16), a experiência de governo da esquerda latinoamericana, e em especial no Brasil, faz parte do último capítulo da esquerda mundial do século XX. Ainda que tenhamos que respeitar as especificidades sócio históricas de cada país, o que parece ter tornado possível a criação de governos ditos de esquerda na América Latina é a conjunção de ao menos duas experiências macropercepetivas: a sensação de impotência diante das primeiras tentativas de içamento econômico após o período das grandes ditaturas - melhor verificado no Brasil durante os oito anos do governo de Fernando Henrique Cardoso -, e a pressão interna por uma maior participação social junto a grupos e parcelas das populações historicamente segredadas. No Brasil, a consolidação e tomada de poder de uma esquerda sindical (mais do que uma esquerda trabalhista) parece ter sido possível justamente pelo agenciamento deste duplo afeto. A imagem do sindicato - com seu derivativo negociador entre partes incondicionalmente desiguais - passa a ser a imagem regente da operação política como um todo. Trata-se da aderência a uma concepção de política enquanto estratégia de negociação, de uma governabilidade somente possível a partir de gestos mediadores direcionados a uma região comum que, no entanto, agrada e desagrada a todos. Cria-se, portanto, condições para que as democracias sócio liberais se façam presentes, democracias obcecadas pela ideia de centro, de governos autodeclarados de esquerda que fazem da "luta pela conquista do centro" seu objeto mais precioso (SAFATLE, 2017, p. 19). Esta divinização do centro também se estendeu aos partidos supostamente de direita, os quais foram levados a aceitar a conservação de uma espécie de "mínimo social" a ser respeitado em suas tentativas de promover a liberação da economia e a desregulamentação gradativa das defesas trabalhistas e dos direitos sociais.

Acabamos, assim, nos vendo engendrados a uma potente maquinaria de investimento libidinal em nome de uma democracia violenta capaz de produzir consensos, de uma democracia concêntrica que soubesse (ou que estivesse disposta a aprender) a ser gerida por uma espécie de dietética do centro (era preciso, pois, que os apetites estivessem devidamente regulados, que as paixões de esquerda ou mesmo de direita fossem apaziguadas para que a 
gestão do centro se tornasse um exercício possível). A questão é que, da perspectiva do centro, tudo parece estar mais ou menos próximo, mais ou menos distante, mais ou menos violento, mais ou menos compensatório. No entanto, é preciso considerar que a lógica de governabilidade do tipo "mais ou menos" só foi possível à medida que passou a se tornar a própria lógica de gestão da vida e dos nossos modos de subjetivação. Dos joguetes políticos por governabilidade (escancarados e incitados pela grande mídia) à política de nossas pequenas vidas cotidianas: tornamo-nos, todos, seres "satisfeitos mais ou menos". Safatle $(2017$, p. 26) dirá que se trata de um novo "design psicológico", do neoliberalismo enquanto discurso moral que nos coloca em um grande e uníssono mantra: não que não haja saída para a sua crise; a questão é que não há escolha: ou é ele ou é ele.

\section{Um novo design universitário}

A gestão da educação superior nos pareceu igualmente mimetizada por este novo design. As universidades públicas, ao mesmo tempo em que se viram mobilizadas por pautas e políticas socialmente inclusivas (com grandes conquistas neste sentido), acabaram por aderir a estratégias de gestão tipicamente neoliberais. O crescimento qualitativo das universidades enquanto protagonistas de pautas sociais extremamente relevantes (somente possível, diga-se de passagem, mediante o investimento direto do Estado) ${ }^{3}$, foi acompanhado por uma lógica de distribuição de recursos que preconizava uma visão individualizada e escancaradamente competitiva. A lógica da internacionalização a todo custo, a concorrência externa e interna por meio de grandes editais, a meritocrática distribuição de bolsas de produtividade, o financiamento de pesquisas a partir de ranqueamentos pouco humanitários, toda uma moral nitidamente neoliberal para sustentar os proventos de um trabalho de natureza supostamente social. Por mais que o ideário das universidades públicas se colocasse a serviço de um projeto de sociedade, os valores que o subsidiavam pareciam de outra ordem. Retornamos, pois, à ideia de moderação, de que era necessário estarmos mais ou menos vinculados a esse design para que pudéssemos sobreviver, que fossemos mais ou menos competitivos, mais ou menos empreendedores, mais ou menos ávidos para que nos tornássemos merecedores de sobrevivências acadêmicas mais ou menos compensatórias.

Aos poucos, as universidades foram se transformando em 'guetos de luxo': um misto de agências de viagens para colóquios internacionais e consumo de produtos culturais globais com espaço para a produção especializada de um saber cujos resultados, muitas vezes, não são sequer publicados na língua local de seus países (...). Com isso, seus intelectuais foram, cada vez mais, perdendo relevância como referências para a reflexão da sociedade sobre si mesma (SAFATLE, 2017, p. 98).

Embora possa parecer uma visão dicotômica e moralista acerca do suposto papel dos intelectuais acadêmicos junto à sociedade, parece-nos que a captura empreendida acabou por fomentar a cisão entre a universidade e a sociedade civil, um dos motivos pelos quais nos vemos hoje quase solitários em nossa defesa por um ensino superior inclusivo. O próprio

\footnotetext{
${ }^{2}$ Referência à canção Peixes, do grupo Os The Darma Lóvers (2000, álbum homônimo). "Nós morremos como peixes / O amor que não vivemos / Satisfeitos mais ou menos / Todas iscas que mordemos / Os anzóis atravessados / Nossos gritos abafados".

3 “Ao final do governo de dois mandatos de Lula, em 2010, o Brasil havia conhecido um forte processo de ascensão social (...) Foram inauguradas 14 novas universidades federais e realizados mais de 7.000 concursos públicos para professores universitários" (SAFATLE, 2017, p. 82).
} 
direcionamento dos editais públicos de fomento, os quais historicamente privilegiam a pesquisa em detrimento da extensão, é algo que corrobora a tese do trabalho universitário enquanto prática de laboratório ou de gabinete. Considerando que estes mesmos editais privilegiam pesquisadores ou grupos de pesquisa supostamente mais produtivos, e que a própria noção de produtividade está intimamente ligada à aderência à lógica de gestão neoliberal do conhecimento, fecha-se o contorno para a implementação e manutenção deste novo design de universidade. De modo explicitamente ambíguo (assim como a ambiguidade ontológica do próprio neoliberalismo), será preciso pagar a suposta liberdade/autonomia do pesquisar com a moeda de uma cega e silenciosa submissão a avaliações tão opacas quanto perversas. $\mathrm{O}$ dito pesquisador universitário torna-se, doravante, a imagem de um sujeito individual, competitivo, paranoico e necessariamente submisso.

\section{A derrocada e a conquista da micropolítica}

A economia é o método. O objetivo é mudar a alma.

Margaret Thatcher

A derrocada do Estado de Bem Estar Social enquanto projeto de sociedade coloca-nos diante de um perigo tecnicamente ainda mais complexo. Trata-se da irrupção de forças macropoliticamente pesadas e reacionárias (com pautas explicitamente fascistas), ainda que no plano micropolítico atuem com agilidade e destreza. Em todos os âmbitos estas forças se fazem presentes, seja no campo da política, da educação, da governabilidade dos corpos. A captura se dá, entretanto, por um duplo viés: mesmo que individualmente os sujeitos não compartilhem plenamente dos valores preconizados por essas novas-velhas pautas, de uma certa medida estes mesmos sujeitos são mobilizados pela rápida assertiva de discursos que sentenciam a suposta falência do estado social, trazendo ao redor de si uma pseudo ideia de mobilização coletiva. A dimensão micropolítica parece-nos ser menos a das pautas defendidas - em sua maioria bastante ambíguas e contraditórias -, mas a da capacidade de mobilizar corpos e desejos há tempos mais ou menos anestesiados. Sedentos por mobilização, os corpos outrora desidratados emergem febrilmente na fala, nos espaços de disputa micropolítica das redes sociais com o coro de outros tantos corpos mais ou menos recém-mobilizados.

Entretanto, é precisamente a gravidade dessa experiência que nos leva a perceber que não basta atuar macropoliticamente. Porque, por mais que se faça no plano macropolítico, dentro e fora do Estado, por mais agudas e brilhantes que sejam as ideias e as estratégias, por mais corajosa que sejam as ações, por menos autoritárias e corruptas que sejam e por mais êxito que tenham em estabelecer menor desigualdade econômica e social e expandir o direito à cidadania, elas resultam numa reacomodação da cartografia vigente se não se acompanham de um deslocamento no plano micropolítico (ROLNIK, 2016, p. 7).

Trata-se, segundo a leitura de Rolnik, de exercermos uma resistência sobretudo no plano micropolítico, tendo em vista que, uma vez as subjetividades alojadas em uma mesma lógica micropolítica, tudo tende a voltar necessariamente para o mesmo lugar, exatamente aquele do qual supostamente pretendíamos escapar. $\mathrm{O}$ que nos parece bastante desafiador - enquanto exercício ativo de certa saúde política - é resistirmos coletivamente à ideia cada vez mais vigente de que estamos sucumbindo, ou de que sucumbimos, imagens virtuais que atualizam modos de viver entregues à melancolia e ao que parece ser politicamente ainda mais nefasto: o 
ressentimento e má-consciência ${ }^{4}$. Na impossibilidade de fazermos luto do objeto supostamente perdido - Estado Democrático de Direito -, obstrução desejada e arquitetada pelos meios de informação e milícias formadoras de opinião, acabamos por mantê-lo idealizado, colados a ele como condição para existir, como se pensar fora dessa lógica (ou ao menos em uma posição marginal) nos colocasse na condição de utópicos alienados, posição bastante confortável a quem deseja que as coisas continuem exatamente da forma como estão. Ainda com Rolnik (2016), somos provocados a pensar a partir do lugar em que estamos situados (e sitiados), em meio a esse inconsciente-colonial-capitalístico que, embora disponibilize um suposto buffet de possibilidades políticas, as engloba em um único e repetitivo cardápio.

O que muda de uma cultura a outra ou de uma época à outra é a política de desejo predominante, o modo de resposta do desejo à experiência da desestabilização e ao mal-estar que esta provoca. Essa diferença não é nem um pouco neutra, pois cada tipo de resposta do desejo imprime certo tipo de destino às formas de realidade - são distintas formações do inconsciente no campo social (...). São muitas as políticas do desejo face ao desconforto provocado por esse incontornável paradoxo que nos constitui (p. 13).

A questão que nos parece improrrogável não seria a de estarmos dentro ou fora desta lógica, (dado que nunca se consegue estar totalmente dentro ou fora de um inconsciente social), mas a de adquirirmos um determinado plano de visibilidade diante das forças que colonizam nossa experiência imediata, de traçarmos (com nossas pesquisas, escritas e modos de viverjunto) cartografias capazes de nos garantirem alguma possibilidade de trânsito, estando a uma altura suficientemente boa das exigências do tempo presente ${ }^{5}$.

\section{Combatendo o acad(an)êmico-em-nós}

Como trabalhar outras maquinações desejantes quando o que presenciamos em nossos corpos acad(an)êmicos são vetores resultantes do cansaço? Como instaurar outros planos de imaginação política quando a imagem majoritária que nos chega é a de que fracassamos? Como resistir quando nós somos agora o alvo midiático dos ataques? Em outras palavras, como nos mantermos resistentes através do que escrevemos, quando nossa escrita já está, ela mesma, mimetizada a um design do qual deveríamos justamente escapar?

Talvez seja o caso de fabricarmos condições para uma política do Texto, uma tentativa de experimentarmos modos de escrita e de leitura que se ensejem enquanto combate, considerando que,

(...) em todo o texto há uma política que o anima, um sopro político insuflado por forças que concorrem e que, por vezes, se complementam. Não se trata meramente de escrever diferente [embora também possa ser], mas de apostar em uma resistência do sentido diante dos fetiches da cultura - e mesmo da crítica -, considerando que cada escrita traça o mapa de seus próprios combates (COSTA, 2017, p. 23).

\footnotetext{
${ }^{4}$ As ideias de ressentimento e má-consciência retiramos de Nietzsche na leitura oferecida por Naffah Neto: "Quando alguém - qualquer que seja a potência de sua força - é separado daquilo que pode, não lhe resta outra alternativa senão transformar-se num poço de recriminação e de ressentimento, num desejo impotente de vingança, num veneno amargo que corrompe a si próprio e ao mundo que o cerca" (1991, p. 61).

${ }^{5}$ Referência à imagem winnicottiana da "mãe suficientemente boa": o suficiente diz respeito à impossibilidade de completude de toda e qualquer experiência de maternagem, impossibilidade que é, para a sorte do bebê, sua própria garantia de saúde (WINNICOTT, 1975; 1997).
} 
Falamos em gestos políticos que envolvam um tratamento atencioso à linguagem e às experiências de afetabilidade junto aos outros. Introjetada em um compósito mutante de palavras e corpos, a política é aquilo que está sempre em luta pela sua própria existência. Com Rancière (2017) somos conduzidos a pensar no plano político enquanto fabricação de mundos com palavras que criam possibilidades de falar, com frases escritas que criam possibilidades de verificação prática, com maneiras de ocupar as ruas e as praças que criam novas escansões do tempo, decupagens inéditas do espaço, novas formas de constituição do comum. Há, a nosso ver, uma mudança radical de substância: de uma posição egossintônica (conformada a valores e sintomas relacionados às estratificações sociais do tempo presente), a linguagem passa a ocupar o que Rancière (2017, p. 16-17) chama de categoria de dissenso. Trata-se de pensarmos que em todas as séries de discursos - sejam estas do Estado, da mídia e da própria universidade - há um tipo de organização de relações estáveis entre sentido e sentido, uma espécie de consenso entre modos de apresentação sensíveis e regimes de interpretação de seus dados, que quaisquer que sejam nossas divergências de ideias e aspirações, damos conta de perceber (ou nos crermos perceber) as mesmas coisas com um regime de significados que operam com similitude. Este consenso nos leva a acreditar que sabemos o sentido do que se passa em nossos corpos e na própria linguagem da qual acreditamos "fazer uso", que sabemos quais tipos de relações normais há entre uma paisagem do sensível e em seguida o sentido que supostamente esta paisagem deseja nos revelar. No entanto, de acordo com Rancière (2017, p. 17), "o que se pode fazer é produzir efetivamente dissenso na escrita; é no fundo, desfazer essas relações".

Considerando, com Safatle (2017, p. 97), de que não há processo político sem atos de nomeação, e que estas nomeações são igualmente atos performativos capazes de redimensionar a capacidade de movimentação dos coletivos, é possível nos perguntarmos: qual a dimensão política daquilo que estamos a insistentemente nomear em nossas universidades? O que quer aquilo tudo que escrevemos em nossas insistentes, reiteradas e almejadas publicações? A quem estas nossas escritas respondem?

Uma política da escrita se faz sob a lâmina fina de uma atenção capaz de nos ajudar a pensar as escritas que nos assediam, os textos que lemos e que escrevemos, os usos e subserviências da linguagem escrita em nosso presente (COSTA, 2017, p. 14).

Tratemos, então, de direcionar nossos esforços à forma como nos relacionamos com a escrita e com os regimes de liberdade/sujeição que se fazem através destes encontros. A questão mais interessante talvez não seja se somos ou não seres capturados por esses velhos-novos designs (dado que somos e também não somos seres completamente capturáveis), mas o que fazemos com tudo isso que passa e que se passa em nossos corpos na relação com o outro, passagens que se fazem enquanto sombras ético-políticas à luz de um transliberalismo ${ }^{6}$ cada vez mais arguto e audacioso.

No que diz respeito aos textos que lemos e que escrevemos, talvez seja o momento de resistirmos aos "reguladores meritocráticos do gozo" (COSTA, 2017, p. 17), de produzirmos - com nossos textos - mecanismos de resistência à santa trindade "escrever-publicar-produzir", de pensarmos a escrita e a leitura capazes de não apenas responder aos ditames desses tempos-textosmercadoria, mas em instaurar-lhes vacúolos de silêncio, zonas de dispersão e desvio que possam

\footnotetext{
${ }^{6}$ A ideia de um transliberalismo nos parece sedutora e é inspirada na leitura que fazemos de Dardot e Larval (2016), nesta nova razão do mundo que se faz sobretudo transpassando tempos, territórios, valores e culturas. Não se trata de um velho ou novo liberalismo, mas do liberalismo colonizador da própria passagem, sempre na condição de entre, nutrindo-se à medida que transita e que faz tudo passar.
} 
fazê-los tomar outros cursos, ex/cursionar. Pensar o escrever enquanto combate, e mais precisamente o escrever na universidade enquanto combate, eis o que nos obseda. Como pensar em combates que se alojem na dimensão micropolítica sem que deixemos de atuar no plano macropolítico? Como nos mantermos neste dentrofora do combate, reservando à escritura seu silêncio primordial sem, entretanto, nos apartarmos de todas as lutas macropoliticamente urgentes?

Talvez seja o caso de pensarmos nossas escritas a partir de uma mirada outra, nos demorarmos (DERRIDA, 2015) diante das pautas cada vez mais urgentes e dispersas - distante das comprovações, dos conchavos, das propinas éticas e dos familiarismos epistemológicos. Talvez, inspirados em Kafka, tenhamos que reaprender a escrever a partir de nosso próprio esgotamento e a partir de mestres outros, de uma maestria sem imagem a priori, maestria indefensável e improrrogável, dado que se faz à luz da vida e à sombra do tempo presente. Talvez o que possamos agora seja escrever como quem traça um "mapa de seus próprios cansaços" (BARTHES, 2003a, p. 42), escrever para nos aliarmos aos soldados desertores da escrita, para maquinarmos com aquilo que de certa forma se recusa ao engajamento discursivo, uma solidariedade para com o além-de-nós, com essas forças insacrificáveis que, no entanto, só encontram sentido quando um em comum destas se apropria.

Pensar uma política da escrita acadêmica na tentativa, não de empanturrar, mas de resistir ao que Rancière (2017, p. 21) chama de "canibalismo da cultura dominante", uma espécie de apetite sem fim do mundo erudito dito "letrado" em se apropriar das culturas, em obrigá-las a serem culturas para que elas possam se integrar às matrizes do saber erudito. Exercitar uma política da escrita acadêmica como quem pensa ser possível ainda outra revolução, uma tomada de potência (e não de poder) do sentido político de nossos gestos cotidianos de escrita e de leitura, no comprometimento a outras formas de viver-junto nas transitoriedades dos espaços mais institucionalizados dos quais padecemos e que também ajudamos a construir.

Sim, acho que existe um povo múltiplo, um povo de mutantes, um povo de potencialidades que aparece, desaparece, se incorpora em fatos sociais, em fatos, literários, em fatos musicais. Com frequência me censuram por ser inteiramente otimista, idiotamente, estupidamente otimista, de não ver a miséria dos povos. Eu posso me dar conta, mas, não sei, talvez eu seja delirante... mas penso que estamos num período de produtividade, de proliferação, de criação, de revolução absolutamente fabulosas do ponto de vista do surgimento de um povo. É isso: a revolução molecular não é uma palavra de ordem, um programa, é algo que sinto, que vivo através dos encontros, das intuições, através dos afetos, e, também, um pouco, de algumas reflexões. (GUATTARI, 2016, p. 25)

\section{Referências}

BARTHES, Roland. O neutro. Anotações de aulas e seminários ministrados no Collège de France, 1977-1978. Trad. Ivone Castilho Benedetti. São Paulo: Martins Fontes, 2003a.

BARTHES, Roland. Roland Barthes por Roland Barthes. São Paulo: Estação Liberdade, 2003b.

BIRMAN, Joel. Reviravoltas na soberania. In: . Arquivos do mal-estar e da resistência.

São Paulo: Editora Record, 2006. 
COSTA, Luciano Bedin. Ainda escrever: 58 combates para uma política do Texto. São Paulo: Lumme Editor, 2017.

DARDOT, Pierre; LAVAL, Christian. A nova razão do mundo: ensaio sobre a sociedade neoliberal. São Paulo: Boitempo, 2016.

DERRIDA, Jacques. Demorar: Maurice Blanchot. Florianópolis: Edufsc, 2015.

GUATTARI, Félix. Confrontações: conversas com Kuniichi Uno e Laymert Garcia dos Santos. São Paulo: n-1 Edições, 2016.

NAFFAH NETO, Alfredo. O inconsciente como potência subversiva. São Paulo: Escuta, 1991. OS THE DARMA LÓVERS. Peixes (canção). In: . Álbum Os The Darma Lóvers (Loop Discos, 2000).

PUCHEU, Alberto. Samba acadêmico de uma nota só (preparando-me para o carnaval). In: Para que poetas em tempos de terrorismos? Rio de Janeiro: Azougue Editorial, 2017.

RANCIÈRE, Jacques. O que me interessa é tentar pensar em formas de travessia, ao largo e em diagonal, em relação ao trajeto normal dos saberes sociais (entrevista). In: SILVA, Maria C. A.; PADILHA, Paula (Org.). Ao largo. Rio de Janeiro: Pró-Saber, 2017.

ROLNIK, Suely. A hora da micropolítica. Caixa Pandemia de Cordéis. São Paulo: N-1 edições, 2016.

SAFATLE, Wladimir. Só mais um esforço. São Paulo: Três Estrelas, 2017.

WINNICOTT, D. W. A família e o desenvolvimento individual. São Paulo: Martins Fontes, 1997.

WINNICOTT, D. W. O brincar e a realidade. Rio de Janeiro: Imago editora, 1975. 